\title{
Relação EU-TU Eterno no viver de cuidadoras de crianças com AIDS: estudo com base em Martin Buber
}

\author{
I-THOU Eternal relationship in the life of caregivers of children with AIDS: \\ study based on Martin Buber philosophy \\ Relación YO-TÚ Eterno en el vivir de cuidadoras de niños con SIDA: \\ estudio con base en Martín Buber
}

\section{Diego Schaurich'}

'Centro Universitário Franciscano (UNIFRA/RS), Santa Maria-RS, Brasil.Sul. Universidade Federal do Rio Grande do Sul (UFRGS), Escola de Enfermagem, Programa de Pós-Graduação em Enfermagem (Doutorando). Porto Alegre-RS, Brasil.

Submissão: 15/12/2009 Revisão: 14/08/2010 Aprovação: 7/11/2010

\section{RESUMO}

Este estudo fenomenológico objetivou compreender o que é ser cuidadora de criança com AIDS, à luz da filosofia de Martin Buber. A entrevista fenomenológica guiou o encontro com sete cuidadoras de crianças com AIDS, selecionadas em um hospital escola de Porto Alegre-RS, região Sul do Brasil. As informações foram interpretadas à luz da hermenêutica, emergindo a unidade de significação Diálogos "entre" o EU familiar e o TU Eterno. Os diálogos ocorrem na busca por respostas que possibilitem a compreensão do significado das repercussões e desafios ao (con)viverem com a AIDS. Revelam esperanças em mudanças, na cura e no desenvolvimento de vacina. Conhecer a importância desses diálogos, no contexto da epidemia HIV/AIDS, facultará o desenvolvimento de um cuidado de enfermagem que congregue aspectos técnico-científicos e humanísticos.

Descritores: Enfermagem; Síndrome da imunodeficiência adquirida; Espiritualidade; Filosofia em enfermagem; Enfermagem pediátrica.

\section{ABSTRACT}

This phenomenological study aimed at understanding, in the light of Martin Buber's philosophy, what is to be a caregiver of children with AIDS. The phenomenological interview guided the meeting with seven caregivers of children with AIDS, selected in a teaching hospital of Porto Alegre-RS, southern of Brazil. The data were interpreted in the light of hermeneutics, emerging the unit of meaning Dialogues 'between' the familiar I and the Eternal THOU. The dialogues take place in the search for answers that allow the understanding of the significance of the impact and challenges they face while living with AIDS. As well, they reveal hope in changes, in the cure and in a vaccine development. We believe that knowing the importance of dialogue in the context of HIV/AIDS epidemic provide the development of a nursing care that brings together the technical-scientific and humanistic aspects.

Key words: Nursing; Acquired immunodeficiency syndrome; Spirituality; Philosophy in nursing Pediatric nursing.

\section{RESUMEN}

Este estudio fenomenológico buscó comprender lo que es ser cuidador de niños con SIDA, a la luz de la filosofía de Martin Buber. A entrevista fenomenológica dirigió el encuentro con siete cuidadoras de niños con SIDA, seleccionadas en un hospitalescuela de Porto Alegre-RS, sur de Brasil. Los datos fueron interpretados a la luz de la hermenéutica, emergiendo la unidad de significado Diálogos 'entre' el YO familiar y el TÚ Eterno. Los diálogos tienen lugar en la búsqueda de respuestas que permitan la comprensión del significado de las repercusiones y desafíos al (con) vivieren con la SIDA. Revelan esperanzas en cambios, en la cura y en el desarrollo de una vacuna. Conocer la importancia de estos diálogos en el contexto de la epidemia proporcionará el desarrollo de un cuidado en enfermería que reúne los aspectos técnico-científicos y humanísticos.

Palabras clave: Enfermería; Síndrome da inmunodeficiencia adquirida; Espiritualidad; Filosofía en enfermería; Enfermería pediátrica. 


\section{INTRODUÇÃO}

A epidemia pelo vírus da imunodeficiência humana/síndrome da imunodeficiência adquirida (HIV/AIDS) pode ser considerada, atualmente, problema em termos de saúde pública, tanto no nível nacional como mundial, que traz consequências, desafios e implicações para as instituições de saúde e no/para o viver das pessoas que estão direta e indiretamente relacionadas a ela. De acordo com dados do Ministério da Saúde ${ }^{(1)}$, de 1980 até junho de 2008, foram registrados o total de 544.846 notificações, das quais 188.386 entre mulheres, parcela da população que vem se destacando dentre os novos casos de AIDS.

A intensificação desse processo de feminização fez aumentar as notificações de AIDS pediátrica (total de 14.184), sendo a transmissão vertical a principal responsável pelos novos casos de infecção pelo HIV, respondendo por $86,1 \%{ }^{(1)}$. A constatação desses fenômenos que vêm delineando os novos rumos adotados pela epidemia na atualidade, aliada às vivências e experiências do autor no cuidado às pessoas que vivem com AIDS, levaram ao surgimento de inúmeros questionamentos que conduziram à necessidade de se estudar o significado que a mulher cuidadora de criança com AIDS atribui à sua existencialidade.

Isso porque se acredita que, ao entender os sentimentos, as emoções, os desafios e as (im)possibilidades presentes na existencialidade dessas cuidadoras, se conseguirá melhorar as práticas de saúde e, consequentemente, o cuidado de enfermagem, com vistas a propiciar o viver com mais dignidade e autenticidade, no mundo. Sendo assim, propôs-se esta pesquisa que objetivou compreender o que é ser familiar cuidadora de criança com AIDS, interpretando os achados à luz do referencial filosófico buberiano ${ }^{(2-3)}$. Do estudo emergiu a unidade de significação Diálogos "entre" o EU familiar e o TU Eterno, que contém questões presentes na existencialidade da cuidadora de criança com AIDS e que ela desvela por meio da relação dialógica com Deus.

Sendo assim, acredita-se que a grande contribuição deste artigo encontra-se no fato de desvelar as compreensões e relações que cuidadoras de crianças com AIDS estabelecem com Deus, tendo por fundamentação uma filosofia ainda pouco explorada pelas áreas da saúde e Enfermagem. Para tanto, justifica-se sua relevância tendo em vista que outros estudos têm indicado ser a religiosidade/espiritualidade importante fenômeno presente no mundo do cuidado de enfermagem ${ }^{(4-6)}$, assim como no viver de pessoas com HIV/AIDS ${ }^{(7-9)}$.

\section{RELAÇÃO EU-TU ETERNO NA FILOSOFIA DE BUBER}

A filosofia buberiana, de acordo com alguns estudiosos, inscreve-se na vertente da corrente existencial-humanista, uma vez que sua preocupação primordial reside na necessidade de resgatar a humanidade presente na essência do homem $^{(10-11)}$. Seu pensamento desenvolve-se ao redor de dois conceitos que podem ser considerados centrais: a relação e o diálogo. Considera-se, dessa forma, que a relação com o outro instaura um modo de ser no mundo, sendo que é por meio da palavra dialógica que o homem adentra à existencialidade.

Entende-se, assim, que o existir no mundo dependerá da palavra princípio evocada pela pessoa, ou seja, poderá presentificar a relação EU-TU, que se caracteriza por ser um encontro dialógico sempre novo, fugaz e atemporal, ou, então, experienciar o relacionamento EU-ISSO, que é a atitude monológica de uso e experimentação de uma pessoa sobre coisas. Vale ressaltar, ainda, que cabe ao ser humano instaurar a mais autêntica e genuína relação, que é aquela em que a palavra emitida pelo EU busca o diálogo de reciprocidade com o TU Eterno(2).

A relação EU-TU Eterno é o meio através do qual o homem terá a possibilidade de resgatar a essência de seu ser, bem como entrar em relação com o outro, pois "todo TU particular é um reflexo de TU Eterno. É por intermédio de cada TU particular da minha experiência que a palavra primária dirige-se ao TU Eterno"(12). Há que se entender que o estabelecimento desse diálogo com Deus permite o revelar da humanidade e de alternativas para a compreensão dos problemas existenciais ao estar consigo, com o outro e com o mundo.

O EU tem a possibilidade de entrar em relação dialógica com o TU Eterno por meio de encontro interpessoal, uma vez que Deus é considerado um Deus-pessoa, isto é, além de tudo, Ele é também pessoa e, portanto, acessível à relação EU-TU e jamais passível de ser reduzido a um ISSO ${ }^{(2-3,12)}$. Nesse sentido, não caberá ao homem discorrer sistemática e dogmaticamente sobre Ele, pois o TU Eterno é considerado em sua alteridade absoluta. A significação maior dessa relação não está em descobrir o que Deus é em essência, mas o que é, em relação a ele, ser humano. Para o filósofo, não importam as diferenciações conceituais entre religiosidade, espiritualidade, fé e crenças, mas sim o modo como o ser humano estabelece a relação com Deus.

Esse encontro não ocorre em um espaço e tempo (pré) determinados, mas acontece no aqui e no agora, na presença autêntica ao estar com o outro e na possibilidade de abertura à relação existencial. Deus é considerado uma potência transcendente, sem a qual o existir do ser humano estaria limitado a percorrer o mundo sem encontrar significados para os fenômenos que se manifestam ao seu ser-sendo, ao seu devir. Há que se considerar, ainda, que "falar de Deus como TU Eterno, como ser em relação ao devir, exprime a mesma realidade, pois, para Buber, Deus é ao mesmo tempo transcendente e imanente, absoluto e relacional. Deus é totalmente Outro, mas é também o totalmente Mesmo, o totalmente Presente" ${ }^{\prime \prime 12)}$.

O encontro EU-TU Eterno, portanto, é um fenômeno puro, verdadeiro e autêntico, uma vez que o ser humano dialoga com o que há de mais supremo em sua existência, com o que dá sentido ao seu vivido, com o que possibilita que realize as outras atitudes possíveis (a relação EU-TU e o relacionamento EU-ISSO). Para além disso, após sair do "ato essencial da relação pura, o homem tem em seu ser um mais, um acréscimo sobre o qual ele nada sabia antes e cuja origem ele não saberia caracterizar corretamente" ${ }^{\prime \prime 3}$. Esse acréscimo não pode ser compreendido como um conteúdo, mas como uma presença que é força em seu ser. 


\section{CAMINHO METODOLÓGICO}

Trata-se de estudo qualitativo de natureza fenomenológica, no qual é importante apreender o sentido e o significado das vivências do ser-no-mundo, a partir das descrições das situações existenciais, assim como compreendê-lo no âmbito de suas particularidades e possibilidades de ser e de realizar escolhas livres e responsáveis ${ }^{(13)}$. Assim, buscou-se conhecer e compreender as vivências e experiências presentes no vivido de mulheres cuidadoras de crianças com AIDS, permitindo o emergir do fenômeno tal como ele se mostra, o que só é possível quando há suspensão de juízo e de preconceitos por parte do pesquisador.

Desenvolveu-se esta investigação no Ambulatório de Pediatria de um hospital escola do município de Porto Alegre-RS, Brasil, tendo como informantes sete familiares cuidadoras de crianças com AIDS, sendo quatro mães biológicas, duas avós maternas e uma mãe adotiva, as quais foram intencionalmente selecionadas. A equipe médica avaliava as seguintes características da cuidadora que estava com a criança no dia da consulta (frequência de acompanhamento ao serviço e saúde mental), bem como o histórico da família (estrutura e rede de apoio) e, quando compreendiam que estavam de acordo com a proposta do estudo, indicavam ao pesquisador, o qual a convidava para participar da entrevista.

A partir do aceite e da assinatura do termo de consentimento livre e esclarecido (TCLE), iniciava-se a coleta das informações, que ocorreu entre setembro e outubro de 2006. Utilizou-se a entrevista fenomenológica ${ }^{(14)}$, que possibilita o emergir da fala originária do sujeito, com a preocupação de se estar aberto às muitas perspectivas que se apresentam nas descrições do fenômeno; de interpretar de forma compreensiva a linguagem dos informantes; e de perceber seus movimentos como gestualidade que veicula significações. Após o aceite das informantes, as entrevistas foram gravadas em audiotape.

A interpretação das informações fundamentou-se na filosofia hermenêutica ${ }^{(15)}$, que objetiva fazer emergir o sentido originário dos discursos, trazendo para a frente do texto aquilo que até então estava velado, permitindo a compreensão dos aspectos significantes das vivências e experiências do ser humano e, consequentemente, do fenômeno estudado.

Esta investigação foi aprovada pelo Comitê de Ética em Pesquisa da instituição (Parecer $n^{\circ}$ 06-122) e teve como preocupação seguir as recomendações previstas na Resolução 196/96 do Conselho Nacional de Saúde ${ }^{(16)}$, as quais estavam garantidas no TCLE.

\section{DIÁLOGOS ENTRE A CUIDADORA DE CRIANÇA COM AIDS E DEUS}

Esta unidade de significação emanou dos discursos das cuidadoras, em meio às compreensões acerca do que é ser familiar de criança com AIDS e as implicações, repercussões e desafios desse fenômeno em seu vivido. Para além de estabelecer relação dialógica com o TU criança, o EU familiar dialoga, também, com o TU Eterno. Essa relação, considerada a mais verdadeira ${ }^{(2)}$, se revela por meio de duas subunidades: Dialogando com o TU Eterno e Esperanças na vivência do EU familiar.

\section{Dialogando com o TU Eterno}

Esta subunidade apresenta o modo como se estabelecem os diálogos entre o EU familiar e o TU Eterno, os quais se fazem presentes por meio da fé e, ainda, por meio de perguntas e respostas que buscam compreensões acerca do vivido e experienciado ao estar, no mundo, com o outro.

Se eu não tivesse fé agora, o quê que ia sê da minha vida? Eu ia ficá bebendo, fumando, fazendo um monte de coisa, achando que a minha vida é, é,... que não tenho problema nenhum, que a minha saúde é normal como os outros. Não é, né,... então a fé é importante, tem que ter fé, né! (F1).

No depoimento acima se percebe que a fé é reconhecida como importante elemento no vivido dessa cuidadora ao estar-no-mundo com o HIV/AIDS. A fé, ainda, é vislumbrada no encontro com o TU Eterno ao propiciar respostas à existencialidade do EU familiar e às suas relações com o outro e com o mundo. Esses fenômenos, vividos e sentidos, são descritos nos depoimentos a seguir:

Deus vai mostrá como ele (o companheiro) não vai tê a doença, né. Até hoje ele faz exame e não tem, né, daí eu digo que vai se habituá, que a gente vive até hoje junto, né, tamo junto e é, é o que eu te digo, a fé é a base [...] tem que pensá em Deus, Deus é maior, né... (silêncio) (F3).

Tem tanta religião que a gente perde até a fé. Tu vai pra uma religião, tu vai noutra... (risadas)... eu não sei, eu acredito só em Deus! Que eu acho que se Deus não te ajuda, ninguém mais vai te ajudá [...] religião é muito boa, mas a religião boa mesmo é Deus (F7).

As cuidadoras afirmam a importância de Deus em suas vidas, exemplificando quando relatam a não infecção do companheiro, mesmo mantendo relações sexuais sem o uso do preservativo. Também, referem questionar a quantidade de religiões existentes e as desvinculam da fé em Deus, o qual as ajuda no (con)viver com a epidemia da AIDS. Os diálogos que o EU familiar estabelece com o TU Eterno podem ser vislumbrados abaixo, quando é revelada a necessidade de se conformar com a sua existencialidade e com as suas relações consigo, com o outro e com o mundo:

Sabe, minha vida, pra mim... (silêncio)... pra mim tá sendo boa, porque eu tô enfrentando as coisas, eu tô me tratando, né, tenho um pouco de medo, assim, de algumas coisas, né, mas depois eu peço assim pra Deus que Ele me dê vida pra eu podê vê os meus filho tudo grande, né (F3).

Eu acho que no momento que Deus tiro a (nome da filha) de mim, ah... (silêncio)... no momento de cada dor Ele qué ensinar alguma coisa, eu acho, porque eu fiquei dentro do 
(nome do hospital), na frente da estátua que nós temo lá no saguão, eu perguntei pra Ele o quê que Ele queria me dize aquela hora, com aquele sentimento tão ruim que eu não tinha conhecido ainda, porque é o sentimento mais forte, é um sentimento assim, devastador! (F6).

A fé aparece como meio de ressignificar o vivido após a descoberta de se ser portador do HIV, bem como por estar convivendo com uma criança que tem AIDS. O diálogo que as cuidadoras estabelecem com Deus Ihes possibilita compreender suas experiências e, assim, tornar a vida mais tranqüila. Ao estar com o TU Eterno, o EU familiar vivencia um encontro autêntico e acredita que a força para viver se faz presente a partir dessa relação dialógica.

\section{Esperanças na vivência do EU familiar}

Esta subunidade revelou as esperanças presentes nas vivências do EU familiar ao estar em relação dialógica tanto com o TU criança com AIDS como com o TU Eterno. É em Deus e para Deus que as familiares cuidadoras voltam seu diálogo na busca de respostas às suas necessidades e dificuldades existenciais, ao cuidar de uma criança com AIDS, especialmente no que tange a possíveis mudanças que se possam fazer presentes no seu processo de viver, bem como esperanças de cura e de desenvolvimento de uma vacina anti-HIV.

No depoimento que segue podem-se perceber as esperanças de mudanças lançadas em direção a/e dialogadas com o TU Eterno, que o EU familiar desvela ao estar-com, existencialmente, o TU criança com AIDS:

Quanta coisa tá pra acontecê, né, quantas mudanças porque só esses remédios que ele toma é fora de sério, né, porque, a carga viral dele tá abaixo de 50, né, os CD tá 1000 e pouco. Quer dizé, ele tá superbem, superprotegido, né, só que por tá ali, a gente sabe que o vírus tá ali, né. [...] E a AIDS, eu creio que uma pessoa pode morrer de velha, pelo menos é a minha esperança de vê meu filho, Deus sabe disso, nem vê porque eu vô morrê antes que ele, né, mas que ele morra de velho, porque se tu vê ele saudável como ele é, lindo, sabe (F2).

Para além dos diálogos que se estabelecem em torno das mudanças existenciais ao conviver com a criança com AIDS, a cuidadora desvela, também, esperanças relacionadas à cura dessa epidemia, como pode ser vislumbrado nos excertos abaixo:

Daqui pra frente a gente tem que lutá pra, pras coisas meIhorá cada vez mais, né. Falam em cura, em coisa assim, né, se vier, já tamo tratado pra se curá mesmo, né, tomara a Deus, porque eu sô, nesse ponto assim eu sô bem, bem objetiva assim, gosto de fazê tudo que tem que faze, né, pra dá certo e lutá por eles, que eles também não pediram, né, pra vim e pra tê um poblema (F3).

... A gente sabe bem, bem no fundo do coração da gente, e Deus sabe disso. É um poblema bem sério. Tu não tem certeza assim? É um poblema bem sério isso aí, é a coisa... tomara que venha essa cura! (F4).

As crenças e esperanças relacionadas à cura da AIDS aparecem nas falas das cuidadoras como expectativa que se faz presente em seu vivido e apresenta relação com os diálogos que estabelecem com o TU Eterno. A cura é compreendida como algo que pode vir a acontecer e que se apresenta como possibilidade de solucionar os problemas advindos da infecção e das demais implicações dela decorrentes, não só à criança com AIDS, mas também aos demais indivíduos portadores do HIV.

Ao estar dialogando com Deus, as cuidadoras também desvelam suas expectativas no desenvolvimento de uma vacina, como se percebe nos seguintes depoimentos:

Daqui uns tempo, de repente, já vai saí a vacina e tu pode tomá a vacina e daí pronto, fica bom eu disse pra ele (criança com AIDS), daí tu não vai mais precisá tomá remédio. Mas enquanto não saí a vacina, a cura, nós vamo tê que tomá os remédio, e Deus vai nos ajudando (F2).

O meu sonho é que venha a, a vacina, né, tomara a Deus! [...] Elas têm caras de gurias bem normais e vamos lutar até o que dé, né! Eu tenho muita fé nessa vacina que tá vindo, essa é a minha fé, porque vai chegá uma hora que vai ter tudo isso aí. Então eu penso, no meu pensamento, assim, que um dia vem a cura! (F4).

Ao encontro dos diálogos com Deus que revelam as esperanças do EU familiar para a cura da AIDS, também aparecem as crenças e expectativas, vividas e experienciadas, na possibilidade de desenvolvimento de uma vacina. Percebe-se que as cuidadoras associam a vacina como algo complexo, aparecendo na relação dialógica com o TU Eterno. Isso pode ser vislumbrado quando descrevem a vacina como um "sonho", estando sua fé voltada para essa esperança, o que traz implicações e repercussões à sua vida.

\section{COMPREENSÕES ACERCA DAS RELAÇÕES E DIÁLOGOS ENTRE O EU FAMILIAR E O TU ETERNO}

Dos discursos das cuidadoras de crianças com AIDS pode-se descortinar as relações e os diálogos estabelecidos com o TU Eterno, seja em virtude de suas próprias experiências quanto em virtude do vivido com a criança e das (con)vivências com a epidemia HIV/AIDS. Isso porque o encontro dialógico com Deus é descrito como relação que possibilita respostas sobre sua existência ao estar convivendo com a infecção pelo HIV, bem como para significar sua relação com a criança com AIDS. Nesse sentido, percebe-se que a fé aparece como algo importante à vida daqueles que se descobrem (con)vivendo com a AIDS e, também, como meio que possibilita o encontro do EU familiar com o TU Eterno.

Vislumbra-se que a fé, como possibilitadora do diálogo com o TU Eterno, é considerada fundamental nas vivências e experiências do EU familiar ao estar com AIDS. Percebe-se 
que a fé propicia à familiar cuidadora compreender os significados de estar passando por dificuldades ao conviver com o HIV, além de dar sentido à sua vida. Assim, "como fonte de interpretação para os acontecimentos da vida, a religiosidade pode representar apoio para o enfrentamento das dificuldades e para as mudanças de atitude"(7). A fé, então, aparece para além de um meio para estar-com Deus, mas como elemento importante por possibilitar à familiar compreender o que se apresenta ao seu vivido. É na relação dialógica com Deus que ela busca significações e associações entre sua saúde e o que faz como ser-no-mundo.

Pode-se compreender que a fé do EU familiar lhe possibilita o estabelecimento da relação dialógica com o TU Eterno. É no diálogo com Deus que as cuidadoras conseguem respostas às suas vivências e experiências como ser-no-mundo, além de possibilitar a elas significar a relação com o outro, em especial com o TU criança com AIDS. Sendo assim, Deus se faz presente na vida dessas mulheres como uma força que dá sentido ao vivido ${ }^{(7,9,17)}$.

O TU Eterno aparece nos diálogos com o EU familiar como se fosse um conselheiro, um dos polos da relação interpessoal que propicia reflexões acerca da vida e do futuro. É de Deus que as familiares cuidadoras esperam respostas para os desafios que se apresentam em sua existência como, por exemplo, o relacionamento amoroso com o outro, a ajuda nos momentos de dificuldades e as preocupações em relação à infecção ou não do parceiro.

Faz-se importante destacar que o TU Eterno é absoluto e relacional, ou seja, é um ser supremo e transcendente, estando presentificado no mundo, no outro e no EU, mas também não pode ser separado da realização da comunidade humana e, por isso, é um ser de relação, que possibilita o encontro por meio do diálogo(2). Deus, então, precisa ser considerado "no mundo de todos os dias, em que os homens realizam sua existência. É no diálogo da vida humana, constituída pelo espírito que essa possibilidade de encontro último surge"(12).

Em meio a esses diálogos, aparece, ainda, a associação entre o TU Eterno e a religião; porém, na compreensão do EU familiar, a religião emana em meio a questionamentos e descrenças, descrevendo que o importante é ter fé em Deus, o qual se revela uma "religião boa mesmo". A religião é instrumento criado pelo ser humano para estar-com Deus, no entanto, o diálogo só acontecerá entre eles quando o ser humano estiver aberto e disposto, de forma autêntica ${ }^{(2-3)}$. Há que se evitar que o TU Eterno "possa tornar-se objeto no mundo para ser explorado, seja em nome da religião ou de qualquer outro sistema dogmático"(11).

Assim, os diálogos EU-TU Eterno fazem parte do existir da cuidadora ao (con)viver com a epidemia da AIDS nas mais diferentes situações cotidianas, como quando significa sua vida e tenta se conformar ao estar infectada pelo HIV, ou quando busca respostas para enfrentar a perda de uma pessoa significante. Deus, assim, está presente e é presença incondicional no vivido por essas familiares cuidadoras, sendo que "a espiritualidade, a fé e as crenças lhes dão forças necessárias para o cuidado e autocuidado e [para] não se sentirem solitárias na luta pela vida"(7). O TU Eterno, ainda, é o mediador nas situações cotidianas compartilhadas com o TU criança com AIDS, ajudando, ensinando e significando para um viver mais pleno e tranquilo.

Percebe-se que essas mulheres compreendem e significam suas existencialidades, bem como as implicações e desafios presentes ao estar, no mundo, (con)vivendo com o HIV/AIDS, a partir do diálogo com o TU Eterno. Suas crenças, desconfianças, esperanças e fé auxiliam-nas a suportar as dificuldades que se manifestam no dia a dia, e a projetar o futuro ${ }^{(9,17)}$. Assim, a relação dia-logal e dia-pessoal com o TU Eterno é vivida em sua plenitude ao ter como possibilidade um encontro com o seu próprio EU, com o outro (TU) e com o mundo.

Além disso, no descortinar dos discursos entende-se que as familiares cuidadoras deixam emergir suas crenças e expectativas relacionadas ao vivido e ao futuro da criança com AIDS. Porém, a relação que estabelece é voltada para o TU Eterno, dialogando acerca das esperanças relativas às mudanças que possam vir a acontecer em suas vidas e no contexto da infecção pelo HIV. O tratamento antirretroviral que possibilita redução da carga viral e aumento das células de defesa $\left(\mathrm{CD}_{4}{ }^{+}\right)$ aparece como importante mudança percebida pela familiar, conforme já encontrado em outros estudos ${ }^{(9,18)}$.

Entende-se que o ser humano "só pode corresponder à relação com Deus, da qual ele se tornou participante, se ele, na medida de suas forças, à medida de cada dia, atualiza Deus no mundo"(2). Assim, as familiares, ao estarem em relação dialógica com o TU Eterno, depositam Nele esperanças relacionadas às situações cotidianas que vivenciam no compartilhar de experiências com a criança com AIDS. Percebe-se, ainda, que Deus é presença ativa, atual e significativa na vida dessas cuidadoras, influenciando suas relações consigo, com o outro e com o mundo.

Ao entrar em relação dialógica com o TU Eterno, as cuidadoras, ainda, relacionam suas crenças e esperanças às mudanças que estão se fazendo presentes ao conviver com uma criança com AIDS, referentes, em especial, à morte. Isso fica explícito quando o EU familiar descreve acreditar que, atualmente, uma pessoa com AIDS possa "morrer de velha" $\mathrm{e}$ tem esperanças de deixar a criança com AIDS neste mundo, vivendo bem e saudável.

O ser humano, como finito no tempo e no espaço, busca no diálogo com o TU Eterno respostas sobre o seu vivido, sobre suas relações existenciais e sobre a essência de seu ser. Essa relação autêntica que se firma com Deus possibilita ao ser humano compreender suas potencialidades e limitações ${ }^{(2,10)}$. Nesse sentido, percebe-se que o EU familiar dialoga com o TU Eterno visando consubstanciar suas crenças e expectativas.

Os diálogos com Deus, então, configuram tentativas para o ser humano buscar respostas e compreensões sobre sua vida e sobre a relação existente entre eles. O ser humano não está interessado em descobrir o que é Deus, mas qual a força que Ele tem sobre suas vivências e experiências como ser-no-mundo e com-o-outro. Isso porque Deus é significado como um ser atual, uma relação "dialogal autêntica exige que o homem se considere não como objeto do pensamento de Deus, mas como pessoa realmente livre, como companheiro 
em diálogo"(12). Assim, quando as familiares desvelam suas crenças na cura da AIDS, buscam, na companhia e no diálogo com o TU Eterno, esperanças para que esse desejo se torne realidade.

Entende-se, ainda, que a vacina, assim como a cura da AIDS, aparece como solução a uma situação que é considerada difícil e que é experienciada no dia a dia ao (con)viver com a infecção pelo HIV, qual seja: a morte. Para essas cuidadoras, a vacina representa a possibilidade última de cura e, portanto, o meio que poderá assegurar vida futura autêntica à criança com AIDS. Seus diálogos com Deus se desdobram em solicitações de ajuda, de atendimento a suas necessidades e desafios existenciais ao estar no mundo com o outro.

Ainda, faz-se importante destacar que esses diálogos que o EU familiar estabelece com o TU Eterno emanam das possibilidades, limitações e expectativas ao conviver com o TU criança com AIDS. Portanto, os diálogos que atualizam as esperanças em mudanças, na cura e na vacina acabam por revelar que o EU familiar está em relação com o TU Eterno, com $\mathrm{o}$ intuito de buscar respostas às suas crenças existenciais. As familiares cuidadoras, por meio de sua fé, buscam em Deus respostas que lhes possibilitem compreender o significado das repercussões e experiências que ocorrem em sua vida ao conviver com a criança com AIDS.

\section{CONSIDERAÇÕES FINAIS}

Este estudo permitiu dar visibilidade a uma temática considerada complexa e de delicados desdobramentos, que é fenômeno presente nas vivências e experiências humanas e, cada vez mais, relacionado às situações de saúde e de doença que acometem a população. Em especial no contexto da epidemia da AIDS, os diálogos com Deus têm sido considerados elementos essenciais de enfrentamento às diversas questões a ela relacionadas bem como representa importante fonte de apoio às pessoas que vivem com a infecção pelo HIV.

Nesse sentido, os achados permitem depreender que as familiares cuidadoras de crianças com AIDS buscam no diálogo com Deus respostas, autênticas e genuínas, que possibilitem significar sua existencialidade e compreender os desafios, necessidades e dificuldades presentes em sua vida e nas relações que estabelecem com o outro e com o mundo. Em meio às perguntas e respostas, atualizadas no encontro dialógico EU familiar e TU Eterno, importantes elementos despontam como a fé, as crenças e as esperanças.

As cuidadoras significam a relação dialógica com Deus como importante fenômeno presente em suas vidas, adquirindo maior relevância frente às facilidades e dificuldades que se manifestam ao (con)viver com a AIDS. Uma resposta do TU Eterno é buscada quando o EU familiar sente medo de infectar seu parceiro, quando tem esperanças em ver os filhos crescerem, quando experiencia a perda de pessoas significantes, quando vislumbra mudanças futuras relacionadas ao tratamento antirretroviral, ao desenvolvimento de uma vacina e à cura.

A relação EU-TU Eterno, portanto, é vivida cotidianamente pelas cuidadoras de crianças com AIDS e as auxilia a entender e superar obstáculos, a tirar ensinamentos dos momentos difíceis e a continuar tendo esperanças e fé. Assim, é importante conhecer as repercussões e implicações que esses diálogos com Deus adquirem no modo como as mulheres cuidadoras significam sua vida e a relação com a criança com AIDS. Ainda, esse conhecimento possibilitará desenvolver cuidado de enfermagem técnico-científico e humanístico, visando potencializar o viver melhor e mais saudável às pessoas que têm HIV/AIDS, a partir de um olhar relacional-dialógico.

\section{REFERÊNCIAS}

1. Ministério da Saúde (BR). Secretaria Políticas de Saúde. Programa Nacional de DST e AIDS. AIDS boletim epidemiológico. Brasília (DF): Ministério da Saúde; 2008.

2. Buber M. Eu e Tu. 5a ed. São Paulo (SP): Moraes; 1977.

3. Buber M. Eclipse de Deus: considerações sobre a relação entre religião e filosofia. Campinas (SP): Verus; 2007.

4. Dezorzi LW, Crossetti MGO. Spirituality in self-care for intensive care nursing professionals. Rev. Latino-Am. Enfermagem. 2008; 16(2): 212-7.

5. Gussi MA, Dytz JLG. Religião e espiritualidade no ensino e assistência de enfermagem. Rev Bras Enferm. 2008; 61(3): 377-84.

6. Paula ES, Nascimento LC, Rocha SMM. Religião e espiritualidade: experiência de famílias de crianças com insuficiência renal crônica. Rev Bras Enferm. 2009; 62(1): 100-6.

7. Silva RAR, Rocha VM, Davim RMB, Torres GV. Ways of coping with AIDS: opinion of mothers with HIV children.
Rev. Latino-Am. Enfermagem. 2008; 16(2): 260-5.

8. Lima AAA, Pedro ENR. Growing up with HIV/AIDS: a study on adolescents with HIV/AIDS and their family caregivers. Rev. Latino-Am. Enfermagem. 2008; 16(3): 348-54.

9. Seidl EMF, Rossi WS, Viana KF, Meneses AKF, Meireles E. Crianças e adolescentes vivendo com HIV/AIDS e suas famílias: aspectos psicossociais e enfrentamento. Psicol teoria Pesq. 2005; 21: 279-88.

10. Von Zuben NA. A questão do inter-humano. Uma releitura de eu e tu de Martin Buber. Síntese - Rev Filosofia. 2008; 35(111): 87-110.

11. Fernandes MA. O que significa dizer Tu? meditação acerca das palavras fundamentais eu-tu e eu-isso. Rev Abordagem Gestált. 2007; 13(2): 195-205.

12. Giles TR. Martin Buber. In: Giles TR. História do existencialismo e da fenomenologia. São Paulo (SP): EPU/ EDUSP; 1975. p. 77-148. 
13. Terra MG, Silva LC, Camponogara S, Santos EKA, Souza AIJ, Erdmann AL. Na trilha da fenomenologia: um caminho para a pesquisa em enfermagem. Texto Contexto Enferm. 2006; 15(4): 672-8.

14. Simões SMF, Souza IEO. Um caminhar na aproximação da entrevista fenomenológica. Rev. Latino-Am. Enfermagem. 1997; 5(3): 13-7.

15. Ricoeur P. Interpretações e ideologias. $4^{\mathrm{a}}$ ed. Rio de Janeiro (RJ): F. Alves; 1990.

16. Ministério da Saúde (BR). Comitê Nacional de Ética em Pesquisa em Seres Humanos. Resolução 196, de 10 de outubro de 1996: diretrizes e normas regulamentadoras de pesquisa envolvendo seres humanos. Brasília (DF): Ministério da Saúde; 1997.

17. Padoin SMM. O cotidiano da mulher com HIV/AIDS diante da (im)possibilidade de amamentar: um estudo na perspectiva heideggeriana. [Tese]. Rio de Janeiro (RJ): Escola de Enfermagem Anna Nery - UFRJ; 2006. 195 p. Doutorado em Enfermagem.

18. Gomes AMT, Cabral IE. O cuidado medicamentoso à criança com HIV: desafios e dilemas de familiares cuidadores. Rev Bras Enferm. 2009; 62(2): 252-7. 